\title{
PROBLEMS IN FORMING COST ESTIMATES FOR CONSTRUCTION INDUSTRY
}

\author{
Sergey Oparin', Nikolay Chepachenko², Marina Yudenko ${ }^{3}$
}

\begin{abstract}
Problems of forming cost estimates for the construction industry is relevant in Russia, where many construction organizations face the issue of a current pricing system that does not consider new technologies in construction. This leads to underestimations of costs in construction and limits opportunity for competitive pricing between construction companies. This article aims to provide recommendations for improving reliability in calculating construction costs and enhance efficiencies in capital investments by construction participants. The article provides an analysis of the existing system of pricing in construction, and the peculiarities of the system of pricing in both Russia and the United States. Results indicate the need for expediency in applying certain provisions of the foreign system into that of Russia's for determining the cost of construction. These measures would help minimize the presence of contractors in the construction market who do not actually perform the construction and installation work on their own, and to achieve the desired level of profitability of 8 to $10 \%$.
\end{abstract}

JEL Classification Numbers: M21, M48, P32, DOI: http://dx.doi.org/10.12955/cbup.v4.759

UDC Classification: 338.51

Keywords: construction, pricing, cost, estimates.

\section{Introduction}

The construction industry is one of the leading spheres of economic activity. This field creates and reproduces the major share of key assets of the country's national economy. In $2014,8.5$ per cent of the economically active population were employed in the construction industry, and construction companies constituted 9.9 per cent of the total number of companies in the country. The annual turnover of construction companies in 2014 was 4929.0 billion rubles, or 3.8 per cent of the aggregate turnover of all companies in the country.

Regarding the foregoing information, it should be noted that a correct and adequate calculation of the cost of construction is important for all participants of the construction market, including investors and subcontractors. Since construction is an industry that consumes resources and thus, requires bank credits for realizing construction projects, the probability of an investor's additional costs in the form of interest on banking, for an unencumbered balance of appropriations, depends on the correctness of the cost-estimate documentation. In addition, the raised amount of investment funds may transpire to be insufficient for completing the project. It is important for contractors at all levels (general contractors and subcontractors) to ensure that the cost estimate of construction and installation works covers all costs of work performed as well as the company's regular profit level. The importance of an objective assessment for the cost of building is underlined in Hackett (2011). Goryachkin, Shtokolov, \& Hayrapetyan (2014) believed that successful functioning in the construction industry of a country depends on the completeness and accuracy of their cost-estimate documentation.

Not surprisingly, there are other factors influencing the effectiveness of construction in other countries. Buzyrev and Yudenko (2013) found that, along with great achievements in mass large-panel house construction, there were a number of drawbacks; the major ones being:

- architectural inexpressiveness and monotony of residential areas that are built-up with largepanel house; and

- operational drawbacks, such as, higher noise levels and penetration of air and moisture through joints.

\footnotetext{
${ }^{1}$ Oparin Sergey, Head of the Chair of Economics and management in the construction Petersburg State Transport University Emperor Alexander I, Saint-Petersburg, Russia, oparinsg@mail.ru

${ }^{2}$ Chepachenko Nikolay, Department of Economics and management in construction Petersburg State Transport University Emperor Alexander I, Saint-Petersburg, Russia, nvchepachenko@mail.ru

${ }^{3}$ Yudenko Marina, Department of Economics and management in construction Petersburg State Transport University Emperor Alexander I, Saint-Petersburg, Russia, mnuspb@mail.ru
} 
Pratt (2012) identified five price categories considered in the pricing of an estimate: labor, equipment, materials, subcontractors, and job overheads. He identified three general reasons why project costs may exceed estimated prices: takeoff quantities are too low; actual productivity does not meet anticipated productivity; and subcontractors or material suppliers fail to meet obligations.

The importance of this article is determined by the necessity for institutional transformations of the entire system of price formation in the Russian Federation. The concept 'basic provisions of pricing and cost estimate standards setting for construction industry in conditions of developing market relations' depicts, among the main aspects of cost estimate formulation in construction industry, the necessity to abandon rigid regulations and centralization in forming and approving construction cost estimates based on market prices as well as the possibility of a wider choice of regulatory framework.

Novak (2011) believed that the state budget had insufficient funds for active participation in private entrepreneurs' business projects, and this decreased the governmental share of control over the economy and the opportunity to avail a complete new set of cost estimate regulatory standards (both itemized and generalized), especially considering various conditions of their application that involve investment activity are independent.

In 2003, the Russian Federation completed a transition to a new cost estimate regulatory framework for the construction industry. However, during development of the new regulations some shortcomings that existed in the previous regulations were retained. These included discrepancies between estimate and market cost of resources. There was also, in the new edition, inaccurate rates based on outdated technologies for works performed and inclusion of rarely used materials in the collective list of estimate prices.

\section{Theoretical Frameworks}

For the above reasons, the current cost estimate regulatory framework appears incomplete. To identify the causes of such incompleteness and to formulate the issues with forming cost estimates, it is necessary to examine separate factors in the history of developing prices and cost estimate regulations in the former Union of Soviet Socialist Republics (USSR) and the Russian Federation. This problem has been investigated in several scientific studies (Ardzinov, 2006; Gumba, Ermolaev, \& Uvarova, 2010; Ermolaev, Sborshchikov, \& Shumeyko, 2014).

The systematization of cost estimate standards and regulations took place in the USSR during the 1960s to 1980s. During that period, the country produced several consecutive editions of the cost estimate regulatory framework (CERF) with CERF 1957, CERF 1969, and on the basis of the latter, the cost estimate norms and regulations, CENR IV-84, also known as CERF 1984. For the first time in these regulations, CENR IV-84 incorporated the normative documents for cost-estimate norms and prices, which previously existed as separate documents. This codex of cost-estimate norms and regulations was due to the joint effort of scientific research and design institutes from across the country. The mutually created CERF became unique in its composition and contents. The number of norms and prices included in the CERF 1984 exceeded 300 thousand.

Regardless of the huge volume of work performed, the CERF 1984 regulation was not without drawbacks. Its most significant weakness involved the prices for resources, which were developed by using averages and were strictly regulated by the Soviet government. Often, this method did not allow various working conditions for a particular item to be taken into account. Nonetheless, the fixing of estimate prices was deemed necessary under the centrally planned economy, which existed until 1992.

The transition to a market economy resulted in a lower need for active state regulation of prices, and thus, costs of construction products were jointly developed by client and contractor. Since 1992, the inflation that continues in the country has required widespread use of an updated system of indices to continue renewing prices.

At the same time, there was a necessity for a new cost estimate regulatory framework because the framework in force, as mentioned above, did not meet requirements, due to changes in the construction industry, and had become redundant. The need to develop a new cost estimate regulatory framework arose because of various reasons, including the following:

- outdated technologies and labor practices; 
- 'closed' rates, i.e., an impossibility to expose the specific cost of particular component resources hidden inside the rate; and

- inclusion of material costs in calculating overhead expenses and estimated profits, which led to considerable increase in overhead expenses and higher profits that were inconsistent with commonly accepted levels of profits in the construction industry.

The Russian Federation Committee for Construction adopted a program aimed at developing and implementing a new cost estimate regulatory framework. During the period from the late 1990s to early 2000s, the main regulatory and procedural documents on pricing were prepared and approved, including the 2001 editions of standards and job prices, and the revised list of material resources. The most important distinctive features of the CERF of 2001, as described in Didkovskaya, Ilyina, Mamaeva, \& Konovalova (2012), are listed below:

- Unit prices in the new framework were calculated in accordance with the principle; direct costs of pricing per unit of change were equal to the combined products of resource consumption and their costs;

- In most cases, the cost of basic materials for general construction works was not included in the rate. Thus, adjustment of direct pricing costs when a resource is substituted or selected could be avoided;

- The standards of resource consumption were substantiated, given the use of new technologies, highly productive equipment, and the proliferation of portable power-operated manual tools; and

- The unified technique was developed to calculate overhead expenses, estimate profit by types of works, and set a payroll fund as common calculations.

As presented, the developed CERF was almost entirely effective without major alterations.

However, despite the abovementioned positive changes in the CERF, a specialist estimator, calculating estimate costs of construction of items, could still face several problems that remained unresolved.

One of the possible problems in cost estimate formation is the relatively low accuracy of an items' cost estimate when using the index numbers. This low accuracy is caused by the deficiencies in the indices' fixing mechanism for translating estimate costs into current prices, as well as by insufficient practice of the more accurate, though more time-consuming resource method of calculation. The Russian Federation Ministry of Construction, being a government authority that currently controls price formation in the construction industry, developed the indices for federal and territorial databases on unit prices for every region of the Russian Federation. These indices apply to the full cost of works and are differentiated only by the type of civil housing construction. For other items, there is a single index to calculate the cost of each industrial construction item. Though the above indices were meant for estimating costs for primary investors only, they are widely used by clients and contractors for cost estimates on all stages of costing work approvals and filing certificates of works performed.

This low accuracy problem was resolved in a few regions of the Russian Federation, among which, the more possibly advanced, are Moscow and Saint Petersburg. In these regions, the local authorities in charge of price formation develop monthly updates for indices, converting every separate quotation into current prices in accordance with information about the current cost of resources. Collections of indices for the new edition of the federal database of unit prices are published in Moscow. In Saint Petersburg, the new edition of the local territorial unit prices 'State Benchmark 2012' (Gosetalon 2012), for which 'line-by-line' indices are also produced, is now widely used. Its application is mandatory for calculating costs of construction and repair of items, financed by the state budged.

At the same time, in other regions of Russian, this particular problem remains unresolved. Moreover, there remain several regions of the Russian Federation where the local government has yet to approve a list of unit costs and prices for their territory. Among such regions are Archangelsk and Kurgan Regions, Perm Territory (Region), and other parts of the Russian Federation. For these regions, the method based on local resources, using local average estimate prices issued by local pricing authorities, will be the most accurate for calculating budget cost estimates.

The contemporary level of automation in cost calculations equalizes time and effort required for cost estimates between the basis-index method and resource method because all collections of average 
estimate prices at current levels could be installed into any cost estimate program. Developers of estimating programs, such as the State Corporations 'Grand', 'Infostroi', and 'Wizard-Soft', and other companies offer collections of average estimate prices, incorporated into the program as either within a service contract or at an extra charge. Problems arise after transfer of cost estimate documentation from the initial draftsmen and compilers to an auditor, because the auditing process of the cost estimates consumes a significant amount of time. Auditing occurs faster when both the draftsman and auditor use compatible software. However, frequently, this is not the case, and the functionality of information exchange between different estimation software becomes extremely flawed.

The second serious problem arises with construction techniques that have been used for cost estimate norms in the past and which have become obsolete. It should be noted that Saint Petersburg Regional Centre for Price Formation and Development in Construction Industry is the only organization engaged in developing current rates for works in accordance with new technologies. However, the norms and rates developed by this organization, presently, cannot be applied to items of public construction immediately following their development. The new norms and rates, prior to their use, should undergo expert appraisal by the Russian Federation Ministry of Construction and then included in the published lists of norms and rates. This is a time consuming process, but it complies with the established procedure.

The third problem arises from discrepancy between the market price and the budgetary estimate cost of all types of resources. First, it concerns employees' compensation rates and estimated wages. For example, a 4th level worker has the hourly pay rate of 203.48 rubles, as of October 1, 2015, according to the data from the Saint Petersburg Centre for Prices Monitoring and Expertise. Therefore, the budgetary estimate of monthly wages after tax deduction for personal (and corporate) income tax is 29.7 thousand rubles (Current Tariff Rates for Wages in Construction, 2015). Nevertheless, in experience, a Saint Petersburg's worker, with appropriate qualification, earns an average monthly wage of 43.7 thousand rubles. A similar problem exists, as shown from our analysis, in that the cost estimate of machinery and mechanical equipment is based on the construction technology and equipment being owned by the company. Few giant construction corporations have full ownership of all the necessary range of machinery and mechanical equipment needed for all construction works. For others, the cost of renting such machinery and mechanical equipment is several times higher than the cost of the company owning and maintaining machinery and mechanical equipment, and this difference in cost is not reflected in regulations.

Several contemporary researchers also identify existing shortcomings in the current system of cost formation. For example, Khilko and Vorobyov (2006), in their research, identify the problems found in the works of several regional centers for cost formation, specifically the drawbacks in monitoring prices for material resources, and the lack of quarterly updates of information for conversion indices leading to underpricing of construction and installation works. Based on the research results, Khilko and Vorobyov concluded that: "in Novosibirsk region" and "before 2004 monitoring of prices was carried out only once or twice a year, and indices did not reflect the current level of prices". Furthermore, Novosibirsk Mayor's Office developed their indices improperly by breaching both the law and the market methodology of price formation in construction industry.

In their research, Besedin (2012) noted inadequate applicability of the existing cost estimate regulatory framework to determine construction costs at early stages of project implementation. Under these circumstances, the cost of construction and installation is calculated in the absence of design documentation. At the present time, there are no effective tools or instruments to justify construction prices at a stage when project design documentation is absent. Such a situation increases investment risks, beginning with the early stage of decisions on whether to build a project or not. According to Besedin's opinion, verifying the accuracy of bidding prices on a proposed project is necessary to reduce the risk of inadequate price changes during a contract. Besedin proposed a step-by-step algorithm for consideration and assessment of bids, which could be instrumental in selecting a contractor for performance of works.

A research of price formation on the primary real estate market for residential housing is presented in the work of Ulianova (2007). Ulianova noted that the existing cost estimate regulatory framework was inapplicable to determine housing cost because regulations failed to consider specific factors relating 
to consumer properties of the project, and the result was that they influenced the cost of real estate. Ulianova wrote, that cost estimates usually serve as basic rates for price formation on the primary housing market and determine the bottom of the price range. In Ulianova's opinion, a scientifically proven method of determining the cost of 1-square meter of living space did not exist at the present time.

The abovementioned research works do not completely resolve methodological problems of determining the cost of construction, and hence the importance of this article.

Methodological Approaches to Formulation of Cost Estimate for Construction Projects in Russia and Abroad

Accurate determination of construction costs remains highly important for all participants of construction market, from investors to subcontractors. Because a construction project usually requires investment of borrowed money (a credit line from a bank, as a rule), accuracy in preparing cost estimates and budget documentation can influence various investors with risks, such as, the possibility of additional expenses as in the form of interest percentage on services for an unused part of the total credit amount, or the cost estimate resulting in a total credit amount that is inadequate for realizing the project.

The regulations for construction industry cost estimates currently used in the Russian Federation appear far from complete. The main reason for this seeming inadequacy lies in its foundations, the Unified Norms and Prices 1987 (USSR - ENiR-87), which causes a significant amount of old and outdated norms and prices to remain in use for calculating current budgets and cost estimates, which relate to previous technologies and work productions. At the same time, all works in developing an upto-date system of market price and cost calculation, which has been carried by a large number of scientific research and project production institutions, have today completely folded. As a result, the modern day specialist accountants, in their daily business, continue to use old and expired regulations that are based on work experiences prior to 1991.

Limitations of the current Russian regulations indicates a need for research and study into the most current experience in cost and price regulations in the developed countries of the United States of America (USA) and Europe. The following is a comparative view on the current state of cost calculation business in the USA. It is noted that the term 'project' in USA and in European practices has a meaning covering the entire business cycle, from investment to completion, not purely a set of documents and paperwork, including blueprints and specifications, as it means in the Russian Federation.

Pre-project Stage

At this stage, construction costs, which are also called 'budgetary concept', are calculated for the initial justification of investment in a project. At this stage, any blueprints or documentation are still to be created. Thus, only the natural indicators of the site are known, such as, location and area size, and the proposed number of apartments or hotel rooms and their class in star rating. At this stage, it is possible to use a method of aggregated cost estimates. These include:

1. calculations based on analogies, for example, calculations usually performed on previously completed projects relating to local conditions;

2. calculations based on known costs for separate construction elements, such as, basement, walls, and roofing.

In both cases, the construction company's information can be used, as well as outside information acquired from a database of a specialized company. Accuracy of such calculation may vary within a range of $\pm 20 \%$, which is usually acceptable for an initial decision about project implementation.

The Design Stage

The design stage reveals the precise data about the construction elements of the project, and allows calculations and approximations of costs based on standard rates and measurements (length, area size, and volume) for all construction elements. The result is called a 'footprint calculation', which has an average accuracy of $\pm 10 \%$. For compilation of a footprint calculation, as usual, a database for 
aggregated estimate prices is used. Also, some information from a construction company's own database may be applied.

The Stage of Preparing Construction and Directing the Construction

Estimates compiled at this stage need maximum precision, because the documents form a basis for both the customer and the contractor to formulate their budget for the project. At this stage, the volume and types of works have been identified, and thus, the cost estimates are formed exclusively on the basis of unit prices, which, in turn, narrow to an error range within $\pm 5 \%$. The source of the quotation costs, similar to that in the previous stage, can be outside information, as well as the existing database of the construction company. It is necessary to mention that the calculation based on the unified costs framework is most time consuming, but at the same time, the most accurate one.

The main difference in the system of price formation between the USA and Russia is the level of pricing. In the USA, the information about costs and estimated prices is updated and published annually. The system of indexation is used mainly for connecting the cost of construction to a specific location.

Another difference between the Russian and the USA systems of budget pricing is that in the USA there is no federal government control over price lists and no federal agencies developing and controlling formative principles for budgets and costs. The sources of information on unit prices for construction works in the USA are the company's own database and collections of quotations produced from specialized companies.

Large construction companies typically have their own price lists for unit prices and services. Such price lists are compiled as a result of systemic works on data collection and analysis of results of a company's business activities. These are displayed in statements of completed working hours (reports). Reports are issued periodically, every 1-2 weeks, according to the internal regulation, specific to each organization. Some organizations may have a mutually beneficial exchange of information to expand their databases.

Companies that are specialized in issuing collections of unit prices use the information of construction companies. Among the best-known specialized companies are Marshall \& Swift, F.M. Dodge, Timberline, and R.S. Means Co, with the latter company regarded the most reputable authority in this business. Collections of unit prices are published in both a print and an electronic version, with the latter usually including software for searching necessary information. Results from Chepurnov (2014) show comparative prices of software products that are used for budgetary documentation in the Russian Federation and the USA (Table 1).

Table 1: Comparative costs of programming software to produce budgetary estimates in Russia and the USA

\begin{tabular}{|c|c|c|c|c|}
\hline Characteristics & R.S. Means, USA & $\begin{array}{c}\text { Marshall \& Swift, } \\
\text { USA }\end{array}$ & Infostroy Russia & $\begin{array}{c}\text { MGK GRAND, } \\
\text { Russia }\end{array}$ \\
\hline Product name & $\begin{array}{l}\text { RSMeans Online } \\
\text { Complete Library }\end{array}$ & $\begin{array}{l}\text { Commercial \& } \\
\text { Agricultural } \\
\text { Estimator } \\
\text { Combo }\end{array}$ & $\begin{array}{l}\text { A-zero, version } \\
\text { Personal }\end{array}$ & $\begin{array}{c}\text { Grand-Estimate } \\
\text { Version } \\
\text { Professional }\end{array}$ \\
\hline $\begin{array}{l}\text { Product type (electronic } \\
\text { database/software } \\
\text { complex) }\end{array}$ & $\begin{array}{l}\text { Software complex } \\
\text { (web-interface) }\end{array}$ & $\begin{array}{l}\text { Software } \\
\text { complex }\end{array}$ & $\begin{array}{l}\text { Software } \\
\text { complex }\end{array}$ & $\begin{array}{l}\text { Software } \\
\text { complex }\end{array}$ \\
\hline $\begin{array}{l}\text { USD Price as at Jan 1, } \\
2014\end{array}$ & 1099.95 & 1750.95 & $\begin{array}{r}\text { (17 } 900 \text { Russian } \\
\text { Rubles) }\end{array}$ & $\begin{array}{r}\text { (29 000 Russian } \\
\text { Rubles) }\end{array}$ \\
\hline $\begin{array}{l}\text { Russian Rubles Price as at } \\
\text { Jan 1, } 2014\end{array}$ & 35924 & 57186 & 17900 & 29000 \\
\hline $\begin{array}{l}\text { Location for base } \\
\text { estimates (Federal, } \\
\text { Regional) }\end{array}$ & $\begin{array}{l}\text { Federal for the } \\
\text { USA and Canada }\end{array}$ & $\begin{array}{l}\text { Federal for the } \\
\text { USA and Canada } \\
\text { with some } \\
\text { foreign cities }\end{array}$ & $\begin{array}{l}\text { Federal (with } \\
\text { limitations) }\end{array}$ & $\begin{array}{l}\text { Federal (with } \\
\text { limitations) }\end{array}$ \\
\hline
\end{tabular}


As shown in the comparison (Table 1), price levels for comparable software programs are somewhat similar.

\section{Results}

It is necessary to stress that USA and Russian cost-estimate databases have several differences, including structure and content of expenses related to a unit rate. The comparison provided below uses the unit prices published by the R.S. Means company.

In the USA, the rate obtained from the cost-estimate database covers all basic materials as well as overhead expenses and estimated profit. The amount of overhead expenses and estimated profit is not shown directly. It is noted in comments that the profit of a construction company is considered to be $10 \%$ of the amount of direct costs. It can be calculated that overhead expenses constitute approximately $41 \%$ of the construction workers' wages. In the Russian practice, a collection of unit rates provides direct costs only, which consist of the main wages, the cost of machinery operation, and the cost of auxiliary materials. In the Federal database of unit rates, the cost of basic materials is generally included in the unit rate. Territorial databases, in most cases, do not include the cost of basic materials in the unit rate. Therefore, this cost should be considered as an addition. Overhead expenses and estimated profit should also be considered additionally; the regulatory standards are adopted in accordance with relevant methodological documents.

In the rate from the USA cost-estimate database, the overhead expenses and estimated profit are set for a contractor (subcontractor) company performing the works on their own. In the USA system of price formation, the costs and profit of the general contractor are provided as an addition to a summary document similar to the summary estimate in the Russian Federation. It should be noted that federally approved norms for overhead expenses and estimated profit do not exist in the USA. Contractors themselves, while estimating costs, can fix the level of overhead expenses and estimated profit from economic calculations for their organizations. The level of overhead expenses, set in the unit prices, is the national average and is applied when a contractor for a particular item has not been selected. In the Russian practice, the level of overhead expenses and profit corresponds to costs of the general contractor, and the subcontractor pays the general contractor the sum for the 'general contractor's services', which is calculated as a percentage of the estimated cost of the works.

In the USA, the rate obtained from the cost-estimate database, apart from price indices, contains reference to individuals of the squad (team) and their performance output per shift. Detailed breakdown for each squad is given in the reference section of the collections of unit rates. In the Russian database such information is classified. However, parts of this information can be found in the common norms and prices (CNP), which serves to develop the state itemized construction estimates (SICE) and federal unit rates (FUR). This CNP contains the information about the composition of a squad and the unit labor costs.

In rates from the USA cost-estimate database, the cost of machinery operation is set, taking into account the cost of rent. In Russian practice, the price for machine-hour is calculated on the grounds that the contractor owns the construction machinery.

The USA rates lack classification of workers in terms of ranking by wage scale. Differentiation of wages depends on workers' professions.

In European countries, the principles of cost-estimate price formation, for the most part, are similar to the principles of cost-estimate price formation in the USA, though there are some differences. In Europe, as in the USA, collections of unit rates are issued on the basis of current prices and are updated regularly. Rates include overhead expenses and estimated profit and are focused on contractor (subcontractor). For example, the collection of rates for 'Batiprix', a set of eight volumes, and the collection of 'The Cost of Works in Construction', a set of two volumes designed for calculating the cost of new construction and repairs (reconstruction) on various stages of executing a project, are issued in France. The collection presents aggregate rates for packages of works. These rates are obtained by calculating itemized costs for construction works. Each rate is supplied with brief instructions on how to apply this rate. The rate takes into account the estimated cost (but without reference to actual terrain), which should be met independently, based on wages and cost of materials 
in the particular region. It is also possible to allocate the cost and labor for individual construction operations and thus formulate an analogous unit of price.

\section{Conclusion}

Presently, cost estimates do not reflect the actual costs of either resources or works in general. The cost estimate plays the role of a 'document for the customer', while in experience there is a redistribution of funds between the elements of direct costs and elements of cost estimate.

To practice the proposed measures and obtained results, in particular for improvement in forming the cost estimate regulatory framework in the construction industry, it is necessary to abandon the rigid control over estimated prices for resources and allow the use of market prices, upon agreement between the client and the contractor. Contractors should be allowed to independently determine the level of overhead expenses from the management accounting data of the company. Such measures would facilitate efficient planning and budgeting of a construction company, allowing it to achieve 8 to $10 \%$ level of profitability, and eventually result in better competition in the construction market. This will undoubtedly lead to improvement in the quality of construction products.

\section{References}

Ardzinov, V. D. (2006). Price Formation and Cost Estimation in Construction. Saint Petersburg: Piter.

Besedin, M. A. (2012). Development of Market Methods of Price Formation in Construction on the Basis of Aggregated Estimate Standards. Nizhniy Novgorod State University Architecture and Civil Engineering.

Buzyrev, V. V., \& Yudenko, M. N. (2013). Modernization of Large-Panel House Building- a Way to Provide Economy-Class Housing in Russia and Germany. European Applied Sciences, Volum1: 193-196.

Chepurnov, D. V. (2014). Distinctive Features of Formation of Construction Cost Estimate in Russia and Foreign Countries. Vestnik of Saint-Petersburg State Economic University. Economics, 3, 154-157.

Current Tariff Rates for Wages in Construction (2015). Monitoring center examination and prices. Retrieved from http:// www.cmec.spb.ru

Didkovskaya, O. V., Ilyina, M. V., Mamaeva, O. A., \& Konovalova, O. A. (2012) Estimated pricing as the basis for the formation of the cost of construction. Samara State University of Architecture and Civil Engineering.

Ermolaev, E. E., Sborshchikov, S. B., \& Shumeyko, N. M. (2014). Pricing and estimate regulation in construction. Moscow: Stroyinformizdat.

Goryachkin, P. V., Shtokolov, A. I., \& Hayrapetyan N. E. (2014). Publication the annual collection of reports and practical materials for engineers, quantity surveyors. Association Pricing and budget normalization in the construction. Moscow. Moscow: Union engineers - price calculation.

Gosetalon (2012). St. Petersburg state budget institution "Monitoring Center Examination and price" Territorial estimate and regulatory framework "GOSETALON 2012 edition 2014. Retrieved from http://cmec.spb.ru/tsnb-gosetalon2012-2014.

Gumba, H. M., Ermolaev, E. E., \& Uvarova, S.S. (2010). Price Formation and Budgeting in Construction: educationalpractical guide. Moscow: Publisher Urait.

Hackett, J. A. (2011). The role of cost estimators in UK construction; a case for and steps towards an estimating profession. UK: University of Birmingham.

Khilko, E. V., \& Vorobyov, V. C. (2006). Perfection of the organizational-methodological approaches to the use of financial and price controls and information and analytical support of regional pricing in construction. Proceedings of the universities. Building. 10, 36-44.

Novak, E. V. (2011). Integration of the estimated pricing and budgeting in construction. Moscow: Ekonomicheskaya Gazeta. Pratt, D. J. (2012). Estimating for Residential Construction. New York: Delmar.

Ulianova, O. Y. (2007). Price Formation on the Primary Real Estate Market for Residential Housing. St. Petersburg: St. Petersburg University of Economics and Finance. 